\title{
Effect of Galla chinensis on the remineralization of two bovine root lesions morphous in vitro
}

\author{
Bin Guo ${ }^{1, *}$, Ke-Hua Que ${ }^{2, *}$, Jing Yang ${ }^{3}$, Bo Wang ${ }^{4}$, Qian-Qian Liang ${ }^{4}$ and Hong-Hui Xie ${ }^{4}$
}

The present study aims to evaluate the effect of Galla chinensis compounds on the remineralization of two artificial root lesions morphous in vitro. Sixty bovine dentine blocks were divided into two groups and individually treated with two levels of demineralization solutions to form erosive and subsurface artificial carious lesions in vitro. Each group was then divided into three subgroups, each of which were treated with a remineralization solution (positive control), deionized water (negative control), or $4000 \mathrm{mg} \cdot \mathrm{L}^{-1}$ aqueous solutions of Galla chinensis extract. The dentine blocks were then subjected to a pH-cycling regime for 7 days. During the first 4 days, the daily cycle included 21-h deal and 3-h demineralization applications. The dentine blocks were dealt with the entire day during the remaining 3 days. Two specimens from each of the treatment groups were selected and observed under a polarized light microscope. Data collected using a laser scanning confocal microscope were computerized and analyzed. Galla chinensis extract clearly enhanced the remineralization of both erosive lesion and subsurface lesion patterns in the specimens $(\boldsymbol{P}<0.05)$. The level of remineralization of the erosive lesion by Galla chinensis extract was lower than that of the subsurface lesion $(P<0.05)$. In addition, the remineralization of the subsurface lesion by Galla chinensis extract was higher than that of the remineralization solution $(P<0.05)$. No significant difference between the remineralization of erosive lesions by Galla chinensis extract and the remineralization solution was observed $(P>0.05)$. So Galla chinensis extract has the potential to improve the remineralization of artificial root lesions under dynamic pH-cyclic conditions, indicating its potential use as a natural remineralization medicine.

International Journal of Oral Science (2012) 4, 152-156; doi:10.1038/ijos.2012.45; published online 20 July 2012

Keywords: Galla chinensis extract; pH-cyclic; remineralization; root lesions

\section{INTRODUCTION}

Root lesion such as root caries is one of the most common oral diseases seriously affecting the oral and general health of older people. ${ }^{1-2}$ Considering the different histologic characteristics and pathological processes, the prevention of root caries is more complex than that of enamel caries. In recent years, the Chinese herbal medicine Galla chinensis has been widely discussed as an anticaries agent. ${ }^{3-4}$ Previous studies proposed that Galla chinensis had antibacterial properties that inhibit the growth and acid production of certain cariogenic bacteria, including Streptococcus mutans $3 \mathrm{a}_{3}$ (serotype c, clinical isolate) and Lactobacillus rhamnosus AC $413 * 5$

The aqueous extract of Galla chinensis has also been shown to influence the demineralization and remineralization of enamel hard tissues and act as a detoxifying agent by combining with various metal ions, alkaloids or glycosides to form insoluble compounds. ${ }^{6-7}$ However, studies on the effect of Galla chinensis on the remineralization of early root caries lesions are limited. The remineralization of different types of root lesions (erosive and subsurface lesions) follows different mechanisms. ${ }^{8}$ Therefore, an in vitro $\mathrm{pH}$-cycling model was used in the current study to evaluate the ability of Galla chinensis in remineralizing different levels of root lesions.

\section{MATERIALS AND METHODS}

Galla chinensis sample

Galla chinensis (1 kg) produced in Sichuan Province, China was dried in an oven at $60{ }^{\circ} \mathrm{C}$ for 3 days, finely powdered, and then added to $600 \mathrm{~mL}$ distilled water. The mixture was stirred for $10 \mathrm{~h}$ at $65^{\circ} \mathrm{C}$ and then filtered. The filtrate was re-extracted with distilled water under the same conditions, and the extract was dissolved in $500 \mathrm{~mL}$ ethanol (100\%). After filtration and evaporation of ethanol, the remaining extract was lyophilized to give a powder (Galla chinensis extract, GCE) (yield, $160 \mathrm{~g}$ ). ${ }^{3}$

\section{Specimen preparation}

Bovine incisors were obtained from the same 1-year-old cattle. Immediately after extraction, the bulk of adherent soft tissues were carefully removed with a scalpel. Remnants of soft tissue were removed via vigorous shaking in ice-cold $10 \% \mathrm{NaOCl}$ for exactly $3 \mathrm{~min}$. The teeth were rinsed with cold tap water, and approximately $6 \mathrm{~mm}$-thick annular slices were cut just below the enamel-cementum junction using a diamond-coated band saw under continuous water cooling (Struers Minitom; Struers, Copenhagen, Denmark). The layer

${ }^{1}$ Institute of Stomatology, Chinese PLA General Hospital, Beijing, China; ${ }^{2}$ The Department of Endodontics, Dental College of Tianjin Medical University, Tianjin, China; ${ }^{3}$ The

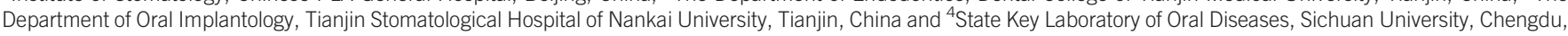
China

*These authors contributed equally to this work.

Correspondence: Dr B Guo, Institute of Stomatology, Chinese PLA General Hospital, Beijing 100853, China

E-mail: guobin0408@126.com

Received 2 November 2011; accepted 8 June 2012 
of cementum was slowly removed using 1200-2 400 grit (Struers), and the pulp was mechanically removed. ${ }^{3}$ Finally, the root slices were rinsed in distilled water and the cut surfaces were coated with an acid-resistant nail varnish, whereas the whole root surface (measuring approximately $4 \mathrm{~mm} \times 4 \mathrm{~mm}$ ) were left uncovered.

\section{Demineralization procedure}

Sixty bovine dentine blocks were divided into two groups and individually treated with two levels of demineralization solutions to produce erosive and subsurface lesion in vitro. Root sections were demineralized by either $0.1 \mathrm{~mol} \cdot \mathrm{L}^{-1}$ acetic acid at $\mathrm{pH} 4.0$ to produce erosive lesions, or a solution of $50 \mathrm{mmol} \cdot \mathrm{L}^{-1}$ acetic acid, $5 \mathrm{mmol} \cdot \mathrm{L}^{-1}$ 4-(2-hydroxyethyl)-1-piperazineethanesulfonic acid (HEPES), $1.5 \mathrm{mmol} \cdot \mathrm{L}^{-1} \mathrm{CaCl}_{2} \cdot \mathrm{H}_{2} \mathrm{O}, 0.9 \mathrm{mmol} \cdot \mathrm{L}^{-1} \mathrm{KH}_{2} \mathrm{PO}_{4}$ and $0.5 \mathrm{mg} \cdot \mathrm{L}^{-1}$ $\mathrm{NaF}$ at pH 5.0 to create caries-like root lesions with pronounced surface layers. Demineralization was performed at $37{ }^{\circ} \mathrm{C}$ for 3 days. ${ }^{8-9}$

\section{pH-cycling conditions}

Each group was randomly divided into three treatment subgroups (10 specimens/subgroup): the experimental treatment, using $4000 \mathrm{mg} \cdot \mathrm{L}^{-1}$ aqueous solutions of GCE; the positive treatment, using artificial saliva as a remineralizing solution ( $\mathrm{pH} 7.0),{ }^{10}$ which contained $1.5 \mathrm{mmol} \cdot \mathrm{L}^{-1} \mathrm{CaCl}_{2}, 0.9 \mathrm{mmol} \cdot \mathrm{L}^{-1} \mathrm{KH}_{2} \mathrm{PO}_{4}, 130 \mathrm{mmol} \cdot \mathrm{L}^{-1}$ $\mathrm{KCl}, 1 \mathrm{mmol} \cdot \mathrm{L}^{-1} \mathrm{NaN}_{3}$ and $20 \mathrm{mmol} \cdot \mathrm{L}^{-1}$ HEPES; and the negative treatment, using deionized water (DDW). The dentine blocks were subjected to a $\mathrm{pH}$-cycling regime for 7 days. Each daily cycle included 21-h dealt and 3-h demineralization applications during the first 4 days. The dentine blocks were dealt with for the whole day during the remaining 3 days.

\section{Polarized light microscopy examination}

Thin planoparallel sections approximately $80 \mu \mathrm{m}$ thick were prepared from the central part of each specimen. Representative specimens were mounted on a glass microscope slide, imbibed in deionized water, and then examined under a polarized light microscope (PLM) (ECLIPSE
ME600L; Nikon, Tokyo, Japan). Digital images were taken using the Nikon ACT-1 for L-1 software (Nikon, Tokyo, Japan).

\section{Laser scanning confocal microscope examination}

A laser scanning confocal microscope (LSCM) (Bio-RAD Co., Hercules, USA) was used to observe eight specimens from each treatment. A specimen slice of about $80 \mu \mathrm{m}$ was stained with a freshly prepared $0.1 \mathrm{mmol} \cdot \mathrm{L}^{-1}$ rhodamine B solution (Aldrich Chem. Co., Milwaukee, WI, USA) for $1 \mathrm{~h}$ without rinsing. The average fluorescence (AF) of the stained baseline and post treatment lesions was then measured.

\section{Statistical analysis}

Data were computerized and analyzed using the SPSS 11.0 software. A Student's paired $t$-test was performed to compare the difference in the treatments before and after observation via LSCM within a group. Independent-Sample $t$-test was used to compare results between the groups, with the significance limit set at 5\% $(P<0.5)$.

\section{RESULTS}

PLM examination results show that the tissue porosity increased with increasing demineralization. The subsurface lesions clearly had intact surface layers. After remineralization, the thickness and density of the surface layer of all specimens treated with GCE and the remineralization solution increased; after treatment, the depth of the lesions were obviously reduced (Figures 1 and 2). However, no significant changes occurred for the DDW group, except for a slight increase in the width of the demineralization layer.

The specimens of the treatment groups before and after $\mathrm{pH}$ cycling were dyed and observed via LSCM; the images are shown in Figures 3-6. GCE obviously enhanced the remineralization of both artificial root lesion patterns (Table $1, P<0.05$ ). The remineralization level of the erosion lesion by GCE was higher than that of the subsurface lesion (Table 2, $P<0.05$ ). In addition, the remineralization level of the subsurface lesion by GCE was higher than that by the remineralization solution.
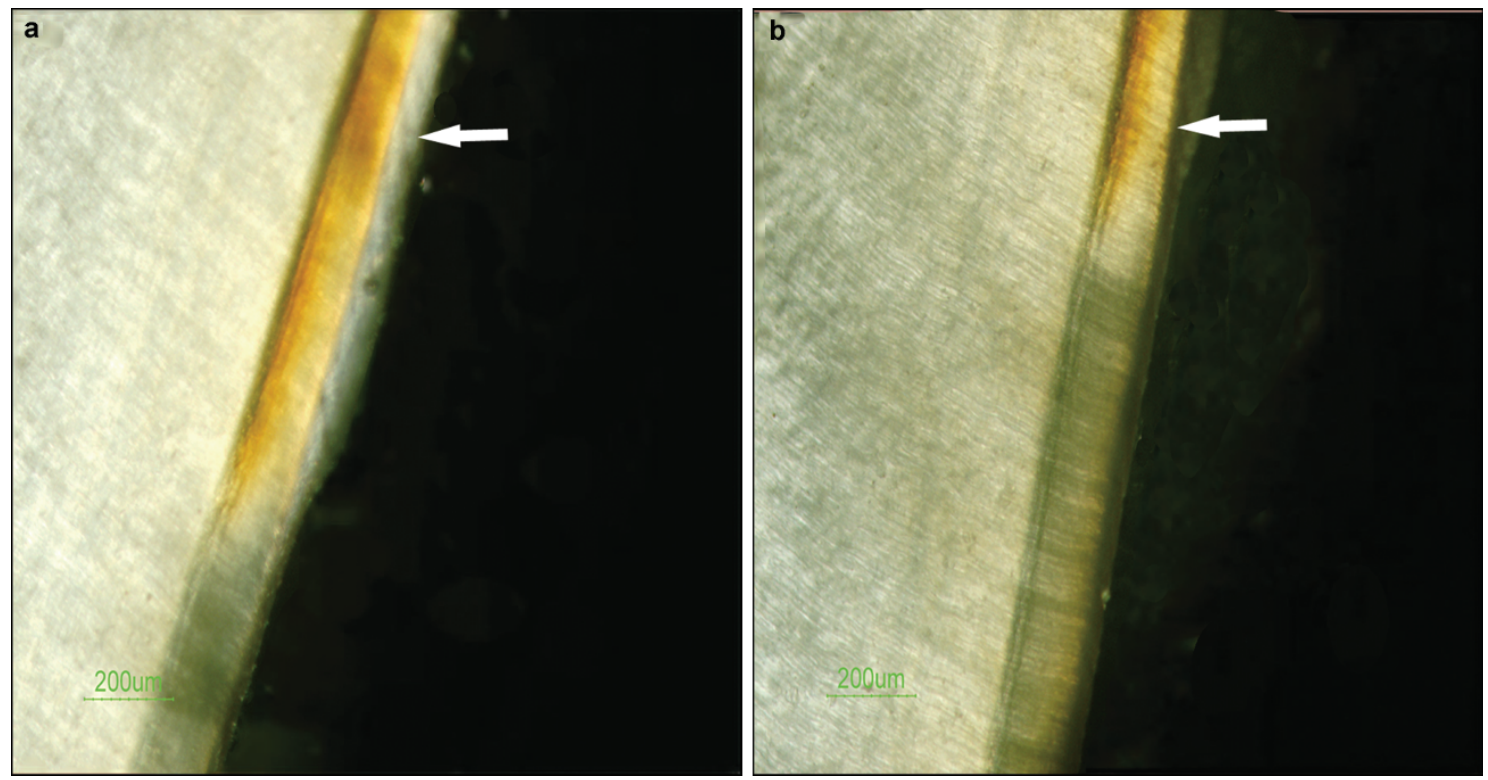

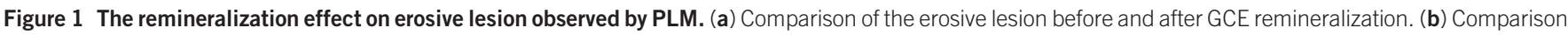

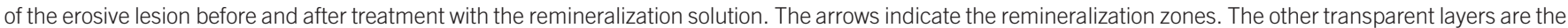
demineralization zones. PLM, polarized light microscopy; GCE, Galla chinensis extract. 

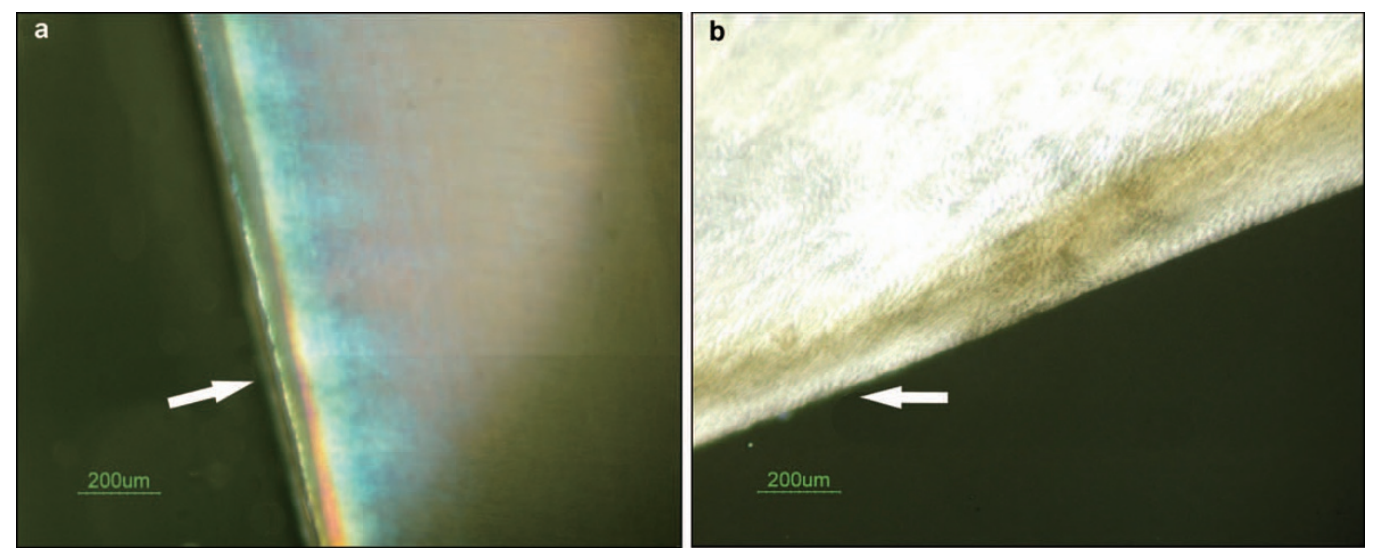

Figure 2 The remineralization effect on subsurface lesion observed by PLM. (a) Comparison of the subsurface lesion before and after GCE remineralization. (b) Comparison of the subsurface lesion before and after treatment with the remineralization solution. The arrows indicate the remineralization zones. The other transparent layers are the demineralization zones. PLM, polarized light microscopy; GCE, Galla chinensis extract.
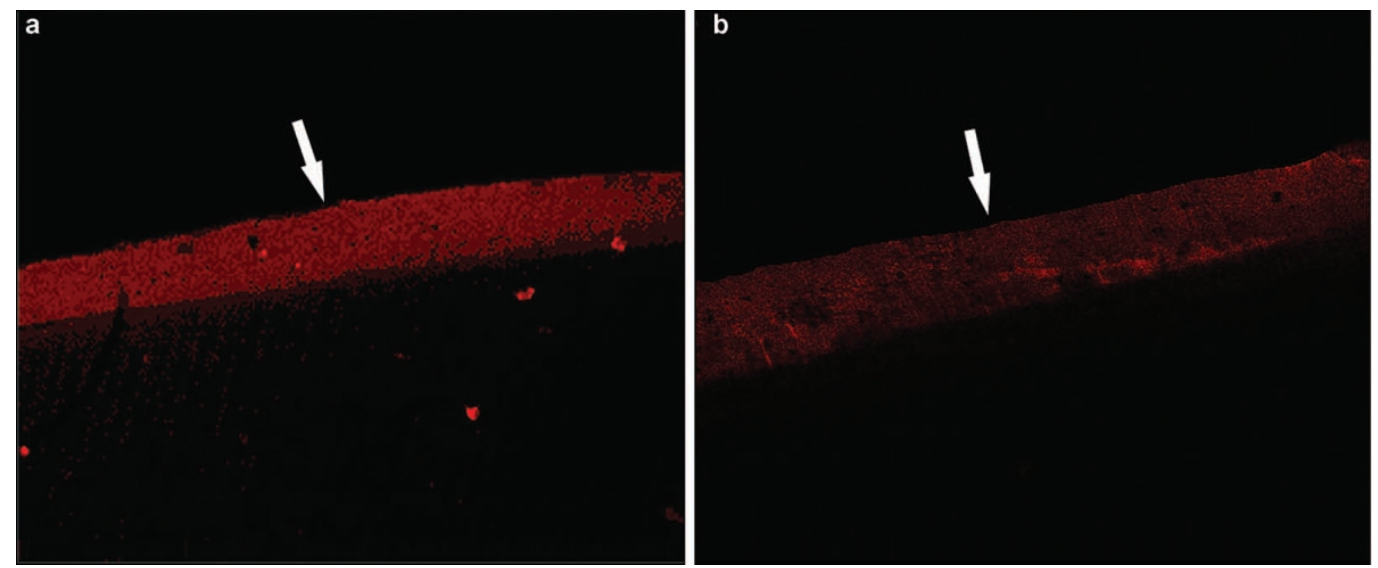

Figure 3 The remineralization effect of GCE on erosive lesion observed by LSCM. (a) Erosive lesion. (b) Erosive lesion after GCE treatment. The areas indicated by the arrows are the fluorescence dyeing zones. The width and density of the fluorescence dyeing zone are related to mineral density. LSCM, laser scanning confocal microscope; GCE, Galla chinensis extract.
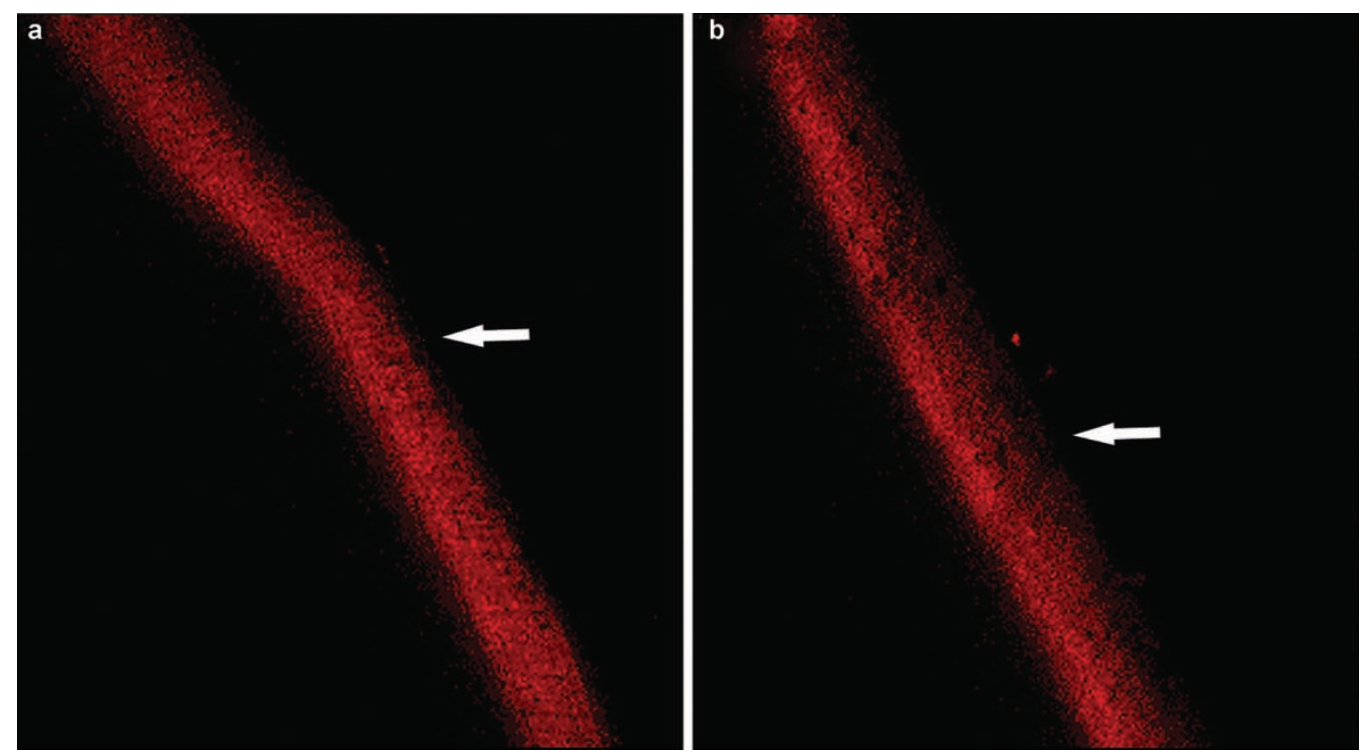

Figure 4 The remineralization effect of the remineralization solution on erosive lesion observed by LSCM. (a) Erosive lesion. (b) Erosive lesion after treatment with the remineralization solution. The areas indicated by the arrows are the fluorescence dyeing zones. The width and density of the fluorescence dyeing zone are related to mineral density. LSCM, laser scanning confocal microscope. 

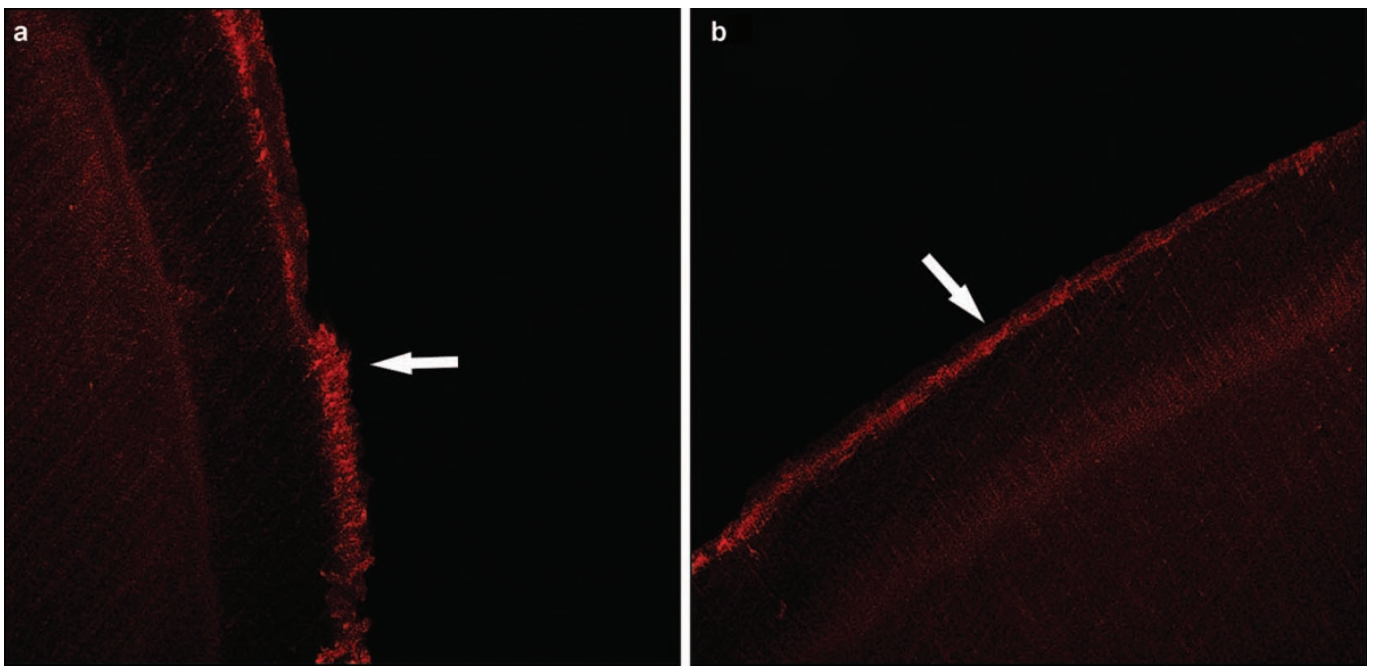

Figure 5 The remineralization effect of GCE on subsurface lesion observed by LSCM. (a) Subsurface lesion. (b) Subsurface lesion after GCE treatment. The areas indicated by the arrows are the fluorescence dyeing zones. The width and density of the fluorescence dyeing zone are related to mineral density. GCE, Galla chinensis extract; LSCM, laser scanning confocal microscope.
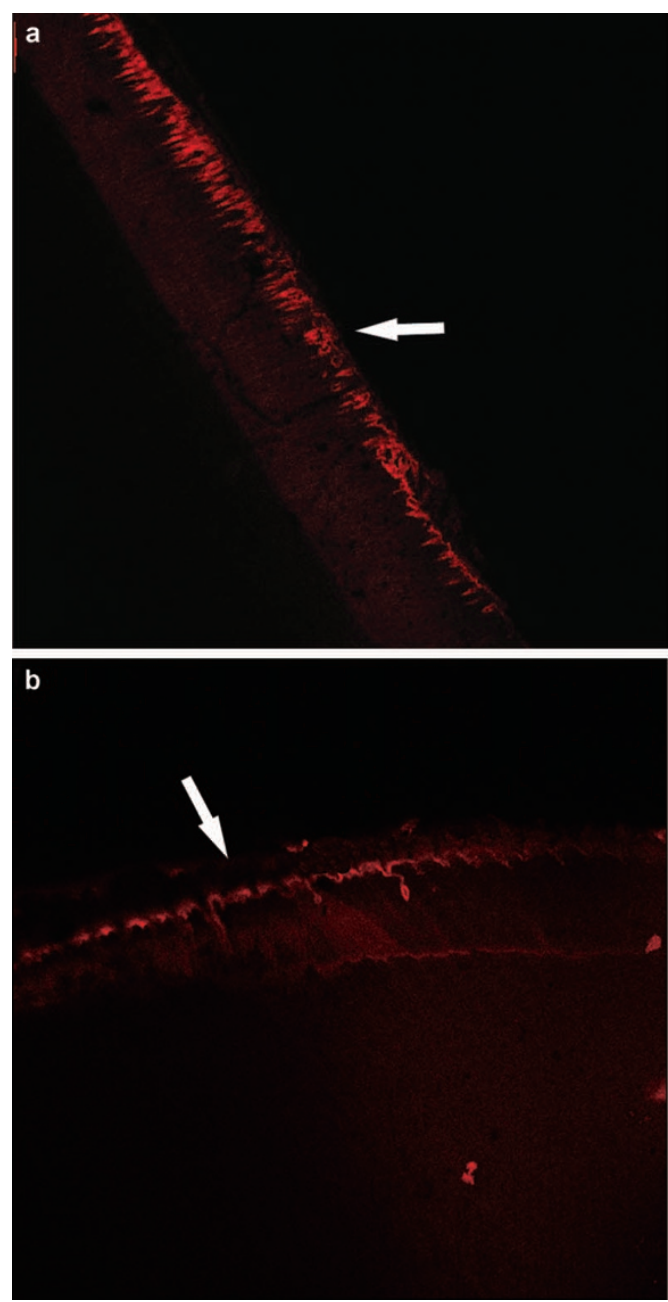

Figure 6 The remineralization effect of the remineralization solution on subsurface lesion observed by LSCM. (a) Subsurface lesion. (b) Subsurface lesion after treatment with the remineralization solution. The areas indicated by the arrows are the fluorescence dyeing zones. The width and density of the fluorescence dyeing zone are related to mineral density. LSCM, laser scanning confocal microscope.
Table $1 \Delta \mathrm{AF}$ and $P$ values obtained via LSCM before and after remineralization

\begin{tabular}{llcrc}
\hline $\begin{array}{l}\text { Lesions } \\
\text { morphous }\end{array}$ & \multicolumn{1}{c}{$\begin{array}{c}\text { Experimental } \\
\text { group }\end{array}$} & $\begin{array}{c}\text { Number of } \\
\text { specimens }(n)\end{array}$ & $\Delta \mathrm{AF}(\bar{x} \pm$ s.d. $)$ & $P$ \\
\hline Erosive lesion & GCE & 8 & $-10.28 \pm 1.71$ & 0.004 \\
& Remineralization & 8 & $-6.20 \pm 1.31$ & 0.002 \\
& solution & & & \\
Subsurface & GDW & 8 & $14.11 \pm 1.14$ & - \\
lesion & GCE & 8 & $-21.77 \pm 3.04$ & 0.000 \\
& Remineralization & 8 & $-7.22 \pm 2.40$ & 0.020 \\
& solution & & & \\
\hline
\end{tabular}

AF, average fluorescence; DDW, deionized water; GCE, Galla chinensis extract; LSCM, laser scanning confocal microscope.

The level of remineralization of the erosive lesion by Galla chinensis extract was lower than that of the subsurface lesion $(P<0.05)$. No significant difference was found for the erosive lesion remineralized by GCE and the remineralization solution ( $P>0.05)$.

Table 2 Comparison of the $\triangle \mathrm{AF}$ values of the GCE and remineralization solution groups

\begin{tabular}{lccc}
\hline & \multicolumn{2}{c}{ Lesions morphous } & \\
\cline { 2 - 3 } Groups & Erosive lesion & Subsurface lesion & $P$ \\
\hline GCE & $-10.28 \pm 1.71$ & $-21.77 \pm 3.04$ & 0.000 \\
Remineralization solution & $-6.20 \pm 1.31$ & $-7.22 \pm 2.40$ & 0.740 \\
$P$ & 0.782 & 0.000 & - \\
\hline
\end{tabular}

$A F$, average fluorescence; GCE, Galla chinensis extract.

$\triangle \mathrm{AF}$ is the difference in the average fluorescence before and after remineralization; a negative value means the occurrence of remineralization; a positive value means demineralization.

\section{DISCUSSION}

The present study investigated the effect of GCE compounds on the in vitro remineralization of two types of root lesions. Before $\mathrm{pH}$ cycling, the subsurface lesion could easily be observed under an intact surface layer through PLM. The artificial specimens used were confirmed similar to natural caries lesions, which exhibit the pathological feature of mineral loss under the surface. ${ }^{11}$ The presence and absence of exposed collagen and the different geometries of the lesions (i.e., the 
distribution of the mineral residue) are the major differences between erosive and subsurface lesions. Heilman et al. ${ }^{12}$ reported that the geometry of the lesions affects iron transport. In the present study, the different remineralization levels of two root morphous by GCE and the remineralization solution were shown.

Collagenous fiber is the major component of the root matrix, which is different from that of enamel caries. Meanwhile, the presence of collagenous fibers is vital to the regrowth of residual crystals during the remineralization of root caries. ${ }^{13}$ Previous studies reported that GCE clearly inhibits collagen fiber degradation by collagenase type I, which is produced by cariogenic bacteria such as S. mutans. ${ }^{7}$ Using another perspective, the present study shows that GCE can promote the remineralization of erosive lesions and that the remineralization of residual mineral crystals can decrease the size of exposed collagen fibers to some degree to inhibit the activity of collagenase. GCE exhibited lower remineralization ability for erosive lesions compared to its ability for subsurface lesions, which may be related to the lower amount and reactive surface area of residual mineral crystals. This result is consistent with the theory that mineral deposition occurs via the regrowth of residual crystals in the lesions rather than by spontaneous mineral precipitation or nucleation on the organic matrices. ${ }^{14-15}$ GCE may play a role in maintaining the shape of root lesions and protecting the residual matrix, including collagen fibers and residual minerals.

The level of remineralization of the subsurface lesion by GCE was higher than that by other experimental groups. Under an intact surface of a subsurface lesion, the root lesion can contain poriferous structures, and exogenous ions or other particles can easily permeate into the demineralized zones. Compared to an erosive lesion, a subsurface lesion has more residual crystals and an intact structure of collagenous fibers prevents the residual mineral crystals from collapsing. The major component of GCE is hydrolyzable tannins, which contain a low proportion of calcium iron $\left(136 \mu \mathrm{g} \cdot \mathrm{g}^{-1}\right)$. However, a similar proportion of calcium iron (about $221 \mu \mathrm{g} \cdot \mathrm{g}^{-1}$ ) in the remineralization solution produced a lower remineralization level than that of a subsurface lesion, implying that some other component of GCE promotes the deposition of mineral ions in the lesions or directly reacts with the residual mineral.

Further research on the mechanism of remineralization by GCE needs to be conducted. Compared with enamel remineralization, the mechanism in root caries is more complicated, because dentine contains not only minerals, but also substantial amounts of collagen and noncollagenous proteins (NCPs). ${ }^{16}$ The effect of NCPs on root caries remineralization is complex; soluble and dissoluble NCPs play completely different roles. ${ }^{17}$ GCE, which is a polyphenol, can react with some proteins and exhibit strong antioxidant and antibacterial activities. ${ }^{18}$ However, whether GCE reacts with NCPs remains to be determined.
The present study demonstrated the potential of GCE to remineralize artificial root lesions under dynamic $\mathrm{pH}$-cyclic conditions. The effect of GCE on root caries can be applied to the prevention of root lesions and may be a promising adjunct or alternative to fluoride. Further research on the mechanism of GCE promotion of root caries remineralization needs to be conducted.

\section{ACKNOWLEDGMENTS}

We would like to thank all the PhD and DDS staff in State Key Laboratory of Oral Diseases, Sichuan University for their help and advice during this study.

1 Nyvad B, Fejerskov D. Root surface caries: clinical, histopathological and microbiological features and clinical implications. Int Dent J 1982; 32(4): 311-326.

2 Fejerskov 0, Nyvad B. Pathology and treatment of dental caries in the aging individual. In: Holm-Pedersen P, Loe H, editors. Geriatric dentistry. Copenhagen: Munksgaard, 1986: 238-262.

3 Ten Cate JM. Review on fluoride, with special emphasis on calcium fluoride mechanisms in caries prevention. Eur J Oral Sci 1997; 105(5): 4461-4465.

4 Featherstone JD. Fluoride remineralization and root caries. Am J Dent 1994; 7(5): $271-274$.

5 Zhao J, Li JY, Zhu B et al. [Study of susceptibility of oral bacteria biofilm to traditional Chinese drug preventing caries]. Hua Xi Kou Qiang Yi Xue Za Zhi 2006; 24(6): 546550. Chinese.

6 Liu ZH, Liu TJ, Li JY et al. [The effect of Galla chinensis on the demineralization of enamel]. Sichuan Da Xue Xue Bao Yi Xue Ban 2003; 34(3): 507-509. Chinese.

7 Li YL, Tang RY, Lu X. [Effects of Chinese nutgall extractum on degradation of collagen in dentine caries]. Ya Ti Ya Sui Ya Zhou Bing Xue Za Zhi 2002; 12(5): 252-254. Chinese.

8 Klont B, ten Cate JM. Remineralization of bovine incisor root lesions in vitro: the role of the collagenous matrix. Caries Res 1991; 25(1): 39-45.

9 Mukai Y, Lagerweij MD, ten Cate JM. Effect of a solution with high fluoride concentration on remineralization of shallow and deep root surface caries in vitro. Caries Res 2001; 35(5): 317-324.

10 ten Cate JM, Duijsters PP. Alternating demineralization and remineralization of artificial enamel lesions. Caries Res 1982; 16(3): 201-210.

11 Theuns HM, van Dijk JW, Jongebloed WL et al. The mineral content of human enamel studied by polarizing microscopy, microradiography and scanning electron microscopy. Arch Oral Biol 1983; 28(9): 797-803.

12 Heilman JR, Jordan TH, Warwick $\mathrm{R}$ et al. Remineralization of root surfaces demineralized in solutions of differing fluoride levels. Caries Res 1997; 31(6): 423-428

13 Lussi A, Linde A. Mineral induction in vivo by dentine proteins. Caries Res 1993; 27(4): 241-248

14 Daculsi G, LeGeros RZ, Jean A et al. Possible physico-chemical processes in human dentin caries. J Dent Res 1987; 66(8): 1356-1359.

15 Hunter GK, Hauschka PV, Poole AR et al. Nucleation and inhibition of hydroxyapatite formation by mineralized tissue proteins. Biochem J 1996; 317(Pt 1): 59-64.

16 Chang SR, Holland GR, Clarkson BH. Effects of phosphophoryn on collagen fibril calcium deposition. J Dent Res 1998; 77(Spec Iss A): 176.

17 Saito T, Arsenault AL, Yamauchi $M$ et al. Mineral induction by immobilized phosphoproteins. Bone J 1997; 21(4): 305-311.

18 Cheynier V. Polyphenols in foods are more complex than often thought. Am J Clin Nutr 2005; 81(1): 223S-229S. creativecommons.org/licenses/by-nc-nd/3.0 